\title{
Flexible Ureterorenoscopy Versus Extracorporeal Shock Wave Lithotripsy for Treatment of Lower Pole Renal Stones
}

\author{
Mohammed B. Ismail, ${ }^{1}$ Hasanain F. Hasan Al-Timimi, ${ }^{2}$ Hayder H. Alwan ${ }^{3}$ \\ ${ }^{1}$ Lecturer, CABMS (Urology), College of Medicine/University of Baghdad, ${ }^{2}$ Ass. Prof, FICMS (Urology), SNBHW \\ (Urology), College of Medicine / University of Baghdad, ${ }^{3}$ M.B.Ch.B, Resident Doctor in Department of Urosurgery \\ in Ghazi Al-Hariri Surgical Specialists Hospital/Medical City Complex
}

\begin{abstract}
Background: Urolithiasis affects 5-15\% of the world population, with high recurrence, (2) which at 5 years can be up to $50 \%$, with high frequency in the labor force population, which produces a high individual and hospital cost, so it constitutes a health problem of high socio-sanitary interes. Objective: To compare the treatment outcomes of Flexible ureterorenoscopy and extracorporeal shock wave lithotripsy for patients with lower pole stones. Patients and method: Data base review for the patients in the period from first of Jan 2018 to the end of June 2019, in which 131 patients underwent interventions for the management of small lower pole stone. Sixty-seven patients were treated by ESWL and the rest (64) treated by F-URS. The most common complication was UTI 9/19 Results: 86/131 were male and 45/131 were female with mean age for F-URS group ( $52 \pm 9.7$ years) and (49.6 \pm 12.3 years) for ESWL group, with highly significant differences regarding the stone size between the studied groups. The treatment rate, operative time and procedure per patient were highly significantly decrease in F-URS group than in ESWL $(p<0.001)$. Moreover, significant association were notice between the studied groups among SFR at 3 months and secondary procedures. Conclusion: lower pole renal stone in size between 10-20 mm treated successfully and more efficiently by F-URS in comparison with ESWL.
\end{abstract}

Keyword: Urolithiasis, Flexible ureterorenoscopy, extracorporeal shock wave lithotripsy, lower pole stone,

\section{Introduction}

The ideal management of renal stones of the lower calyces still continues in controversial discussions and is a dilemma for the urologist. No single method is suitable for removing all stones of the lower calyces. The aim of lower calyceal stones management is to achieve maximum stones clearance with least morbidity. Recently developed minimally invasive procedures have superseded open stone surgery. Extracorporeal shockwave lithotripsy (ESWL), percutaneous nephrolithotomy (PCNL), and flexible ureteroscopy are the presently used therapeutic methods ${ }^{(1)}$. Urolithiasis affects $5-15 \%$ of the world population, with high recurrence, ${ }^{(2)}$ which at 5 years can be up to $50 \%$, with high frequency in the labor force population, which produces a high individual and hospital cost, so it constitutes a health problem of high socio-sanitary interest ${ }^{(3)}$. The increase in the prevalence of urinary lithiasis has been considerable in recent decades, generating an increase in spending on health systems ${ }^{(4)}$.
The first flexible ureterorenoscope (F-URS) was used in 1983, developed by Bagley et al., Giving way to a number of technological advances, until the design of current equipment was achieved with a decrease in caliber associated with a wide working channel that allows use multiple instruments simultaneously, achieving active deflection at its distal end. Likewise, improvements in resolution have been incorporated to achieve a high definition digital image ${ }^{(5,6)}$.

There is a clear and linear relationship between the number of cases and the decrease in surgical times, complication and success rate; however, the complications associated with the use of F-URS remain a matter to be taken into a consideration. Among the complications described is the avulsion of the ureter, with an incidence of $0.5 \%$, which has been decreasing since the beginning of the use of the F-URS, the intussusception of the ureter (defined as the folding of a tract of an organ hollow within the same organ), due 
to a circumferential lesion in the wall of the same. This complication has been associated with the presence of fibro epithelial polyps and transitional cell neoplasms; however, the incidence is so low that it cannot be estimated in the available literature. Ureter perforation is another frequent complication with an incidence ranging from 0 to $15.4 \%$. False routes are another frequent complication that occurs when an instrument pierces the ureteral mucosa without penetrating the total thickness of the ureter wall. Its incidence is low and ranges between $0.4-0.9 \%$. Finally, one of the most feared intraoperative complications is the damage or malfunction of the instruments, however, today this complication has become more anecdotal and the incidence is close to $0 \%$. Among these factors are the malfunction of the laser fiber tip, the breakage of the fiber inside the ureterorenoscope and the breakage of the extractor basket ${ }^{(7)}$.

Extracorporeal shock wave lithotripsy ((ESWL) is the most frequently used treatment modality due to ease of use and great acceptance by the patient ${ }^{(8)}$. The great success in fragmentation and the minimum rate of complications, associated with its non-invasive and frequently ambulatory condition, explain that it still displaces widely all other therapeutic alternatives in urinary lithiasis6 with approximately $80-85 \%$ of the initial indications, ${ }^{(9)}$ especially for non-complex calculi of the upper urinary tract, their resolution rates range from 33 to $97 \%{ }^{(10)}$.

Aim of the study: To compare the treatment outcomes of Flexible ureterorenoscopy and extracorporeal shock wave lithotripsy for patients with lower pole stones.

\section{Patients and method:}

Data base review for the patients in the period from $1^{\text {st }}$ of Jan 2018 to the end of June 2019, in which 131 patients underwent interventions for the management of 10-20 mm lower pole stone. 67 patients were treated by ESWL and the rest (64) treated by F-URS.

All patients underwent CT scan preoperatively to determine the size and location of the lithiasis, as well as the assessment of the approach using URS Flex.

\section{Technique}

The patient's position should not be a very forced lithotomy to facilitate the passage of the protective sheath and the F-URS in a simple way and as straight ahead as possible.

We usually start with the passage of a guide wire through the ureteral orifice until it reaches the renal pelvis or upper calyx and visualize the lithiasis with fluoroscopic control.

Subsequently, and through the guide wire, we pass a dilatation balloon catheter to dilate up to $15 \mathrm{Fr}$ from the ureteral orifice to the iliac ureter in cases where necessary. This is due to the fact that the protective sheath usually has an external caliber of 13-14-15 Fr although the new thinner Flexible URSs allow a smaller caliber.

After dilating the ureter to the iliac junction, we will perform a retrograde ureteropylography that helps us subsequently control the passage of the protective sheath of the F-URS that we use in all cases.

The protective sheath will be passed on the guide wire and will be housed in the renal pelvis. Subsequently we remove the obturator of the protective sheath with the guide wire, leaving only the protective sheath in renal pelvis and the bladder catheter.

The use of the protective sheath of the F-URS, which we use in all procedures, will not only help us improve visibility, maintain low intra renal pressures or facilitate the extraction of fragments, but also considerably lengthens the half-life of the F-URS Flex and it represents a considerable economic saving.

Once we are with the F-URS inside the renal pelvis, we will try to locate the lithiasis and direct it with the help of a basket to a location that allows us to work in a straight line as a superior calyx or renal pelvis.

Working in locations other than the lower calyx is not only important for comfort during litho fragmentation by working in a straight line, but also makes it easier for residual lithiasic fragments that may remain to be expelled spontaneously more easily.

The caliber of the laser fibers used can be 220 microns. This fiber does not allow you any degree of flexion and forcing it can favor F-URS breaks.

The 150-220 fiber allows you all the degrees of flexion that your F-URS has, better visibility by limiting less the wash flow with the counterpart of being able to use less laser power and greater fragility and ease of 
fiber breakage with its additional cost.

The fiber of 220 microns is the one that we use in most cases, it limits you very few degrees and being of greater diameter, allows you greater contact area with the lithiasis and therefore the fragmentation of the lithiasis will take less time in addition to resist greater lithotripsy power and be a fiber more resistant to breakage by handling it. It is important to avoid as much as possible a blood medium since the F-URS washing channel and its flow do not allow a good visualization.

If this happens, we must increase the pressure of the inlet flow without fear of raising intra renal pressures because we always use the protective sheath of the F-URS and maintain a constant intra renal pressure.

Although we use a gravity irrigation system, on certain occasions we use a manual pressure increase using a $60 \mathrm{ml}$ syringe connected to the URS Flex using a saline serum system.

Once the lithotripsy is finished, for which we start with $0.8 \mathrm{~J}$ and $6 \mathrm{~Hz}$ and we increase the energy of the laser depending on the hardness of the lithiasis, we must with the help of nitinol baskets without tip, extract the larger fragments through of the protective sheath avoiding the use of tweezers through the Flex URS that can favor its breakage.

\section{ESWL Technique:}

Patients were took analgesia by diclofenac injection.
In about 3000 shocks ( 80 shocks/minutes) in each session or we continue until the stone was completely crushed. Evaluation of the patients post ESWL by K.U.B. if stone radio opaque and ultra sound if stone is radiolucent to see if there is residual stone. The treatment may reach 3 sessions if there is observation of stone with inadequate fragmentation

\section{Follow up:}

After 3 months, urography or Uro-CT scan were done to the patients to see the outcome. At this time we can assess whether or not there is residual lithiasis and whether they require any type of treatment or not according to their condition. We compared between F-URS and ESWL regarding the treatment and complications rate, SFR, secondary and total number of procedures and duration time of operation.

\section{Results}

131 patients with lower pole renal stone with size 10$20 \mathrm{~mm}$ were enrolled in the current study, 86/131 were male and 45/131 were female with mean age for F-URS group ( $52 \pm 9.7$ years) and (49.6 \pm 12.3 years) for ESWL group, with highly significant differences regarding the stone size between the studied groups. No significant differences were found between the studied groups regarding gender, side of stone, previous treatment of stone, opacity, age, and BMI of the patients (table 1)

Table 1: Pretreatment and demographic data of studied patients

\begin{tabular}{|c|c|c|c|c|c|c|}
\hline \multirow{2}{*}{\multicolumn{2}{|c|}{$\mathbf{N}$}} & \multicolumn{2}{|c|}{ F-URS $(n=64)$} & \multicolumn{2}{|c|}{ ESWL (67) } & \multirow{2}{*}{ P-value } \\
\hline & & \multirow{2}{*}{$\begin{array}{l}\% \\
43\end{array}$} & \multirow{2}{*}{$\begin{array}{l}\mathbf{N} \\
67.2\end{array}$} & \multirow{2}{*}{$\begin{array}{l}\% \\
43\end{array}$} & \multirow[b]{2}{*}{64.2} & \\
\hline \multirow{2}{*}{ Gender } & Male & & & & & \multirow{2}{*}{0.8} \\
\hline & Female & 21 & 32.8 & 24 & 35.8 & \\
\hline \multirow{2}{*}{ Side of stone } & Right & 30 & 46.9 & 31 & 46.3 & \multirow{2}{*}{0.9} \\
\hline & Left & 34 & 53.1 & 36 & 53.7 & \\
\hline \multirow{4}{*}{ Previous Rx. of stone } & URS & 3 & 4.7 & 5 & 74.6 & \multirow{4}{*}{0.3} \\
\hline & ESWL & 8 & 12.5 & 8 & 11.9 & \\
\hline & PNL & 9 & 14.0 & 3 & 4.5 & \\
\hline & Open & 2 & 3.1 & 3 & 4.5 & \\
\hline \multirow{2}{*}{ Opacity } & Opaque & 52 & 81.3 & 57 & 85.1 & \multirow{2}{*}{0.7} \\
\hline & Lucent & 12 & 18.7 & 10 & 14.9 & \\
\hline \multicolumn{2}{|l|}{ Age $($ mean \pm SD) } & \multicolumn{2}{|c|}{$52 \pm 9.7$} & \multicolumn{2}{|c|}{$49.6 \pm 12.3$} & 0.2 \\
\hline \multicolumn{2}{|l|}{$\mathrm{BMI}($ mean $\pm \mathrm{SD})$} & \multicolumn{2}{|c|}{$28.6 \pm 2.3$} & \multicolumn{2}{|c|}{$29.3 \pm 3.5$} & 0.1 \\
\hline \multicolumn{2}{|c|}{ Stone size $(\mathrm{mm})($ mean $\pm \mathrm{SD})$} & \multicolumn{2}{|c|}{$15.3 \pm 1.5$} & \multicolumn{2}{|c|}{$14.2 \pm 2.1$} & $<0.001$ \\
\hline
\end{tabular}


Table 2 show that there is no significant differences were found between the studied groups among stone $\mathrm{H}$. density

Table 2: Association between the studied groups among $\mathbf{H}$ density

\begin{tabular}{|l|l|l|l|l|l|}
\hline \multirow{2}{*}{ HD } & \multicolumn{2}{|l|}{ F-URS (n=64) } & \multicolumn{2}{l|}{ ESW (n=67) } & \multirow{2}{*}{ P value } \\
\cline { 2 - 6 } & $\mathbf{N}$ & $\mathbf{\%}$ & $\mathbf{N}$ & $\mathbf{\%}$ \\
\hline$>1000$ & 23 & 36.0 & 23 & 34.0 & \multirow{2}{*}{0.9 NS } \\
\hline$<1000$ & 41 & 64.0 & 44 & 66.0 & \\
\hline
\end{tabular}

As shown in table 3, the treatment rate, operative time and procedure per patient were highly significantly decrease in F-URS group than in ESWL $(p<0.001)$. Moreover, significant association were notice between the studied groups among SFR at 3 months and secondary procedures.

Treatment and post-treatment data for the studied patients

\begin{tabular}{|c|c|c|c|c|c|c|}
\hline \multirow{2}{*}{\multicolumn{2}{|c|}{ No. }} & \multicolumn{2}{|c|}{ F-URS $(n=64)$} & \multicolumn{2}{|c|}{$\operatorname{ESWL}(n=67)$} & \multirow{2}{*}{ P-value } \\
\hline & & $\%$ & No. & $\%$ & & \\
\hline \multicolumn{2}{|l|}{ Retreatment rate } & 5 & 7.8 & 41 & 61.2 & $<0.001$ \\
\hline \multicolumn{2}{|c|}{ Stone-free rates (SFR) at 3 months } & 53 & 82.8 & 47 & 70.1 & 0.008 \\
\hline \multirow{2}{*}{ Secondary procedures } & ESWL & 5 & 7.8 & 0 & - & \multirow{2}{*}{0.004} \\
\hline & F-URS & 0 & - & 7 & 10.4 & \\
\hline \multicolumn{2}{|l|}{ Operative time (min) } & \multicolumn{2}{|c|}{$75 \pm 31$} & \multicolumn{2}{|c|}{$96 \pm 36$} & $<0.001$ \\
\hline \multicolumn{2}{|l|}{ Procedures per patient } & \multicolumn{2}{|c|}{$\begin{array}{l}1.3 \pm 0.7 \\
\text { Range (1-2) }\end{array}$} & \multicolumn{2}{|c|}{$\begin{array}{l}2.2 \pm 1.4 \\
\text { Range (1-5) }\end{array}$} & $<0.001$ \\
\hline
\end{tabular}

The most common complication was UTI 9/19 (four patients in F-URL group and five patients in ESWL group), eight patients presented with severe pain (5 patients in F-URL group and 3 in ESWL group), and two patients presented with gross hematuria one in each group (figure 1).

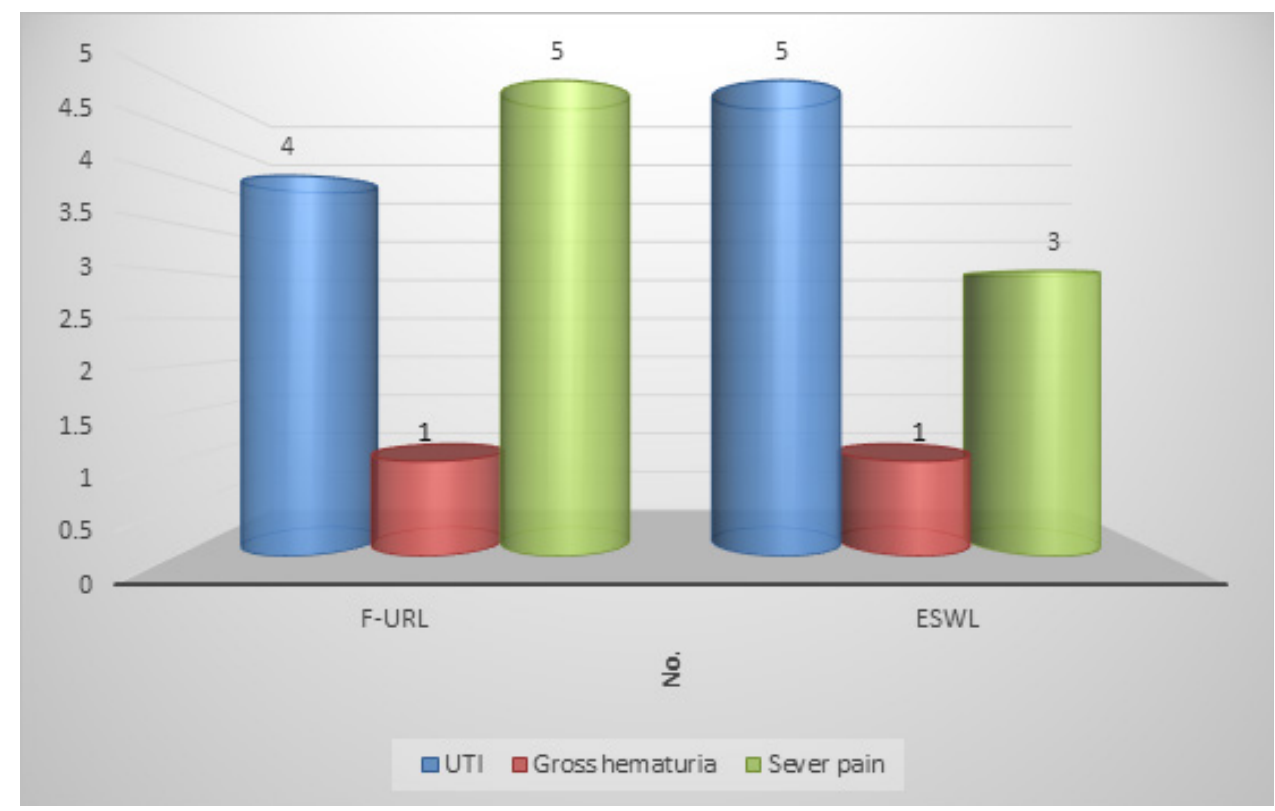

Figure 1: Complications 


\section{Discussion}

Patients and physicians like highly the ESWL way for treatment of renal stone as it is non-invasive procedure despite lower SFR and high percentage of retreatment procedures ${ }^{(11,12)}$, which is considered by many of them (physicians) as first line renal stone treatment. ${ }^{(13,14,15)}$

In spite of highly significant increase of the stone size in F-URS group than that in ESWL group we noticed that the retreatment rate were highly significant decrease in first group which is considered as most important finding in the current study.

SFR at 3 months were better in F-URS technique than that by ESWL with significant association, while in a study carried by Kumar A et al, the SFR at 3 months were better in F-URS $(86.6 \%)$ than that in ESWL $(82.2$ $\%$ ) but with no significant association ${ }^{(16,17)}$. Moreover, it is similar to that found by Pearl et al, but with no significant differences ${ }^{(12)}$.

In the present study we found that urinary tract infection is the common cause of complications in ESWL and sever pain in F-URS, while in study carried by Kumar $\mathrm{A}$ et al, the common complication found in ESWL was sever pain and UTI in patients treated with F-URS.

In a Cochrane analysis, study carried by Srisubat et al (2009) revealed that in three ways of renal calculi stone treatment the ESWL had the lowest efficacy than PCNL and URS but with no significant differences. Moreover shorter period of stay in hospital were found in ESWL than other two procedures, and these three treatments (ESWL, F-URS, and PCNL) looked to offer a good chance of rendering the patient stone free in one $\operatorname{session}^{(18)}$.

\section{Conclusion}

Lower pole renal stone in size between $10-20 \mathrm{~mm}$ treated successfully and more efficiently by F-URS in comparison with ESWL.

Conflict of Interest: None declared.

Funding: None.

Ethical Clearance: was taken from the scientific committee of the Iraqi Ministry of health.

\section{References}

1. Yuri P, Hariwibowo R, Soeroharjo I, Danarto R, Hendri AZ, Brodjonegoro SR, et al. Meta-analysis of Optimal Management of Lower Pole Stone of 10-20 mm: Flexible Ureteroscopy (FURS) versus Extracorporeal Shock Wave Lithotripsy (ESWL) versus Percutaneus Nephrolit. Acta Med Indones. 2018 Jan 1;50:18-25.

2. Labrada MV, Larrea E, Castillo M, Borrero L, Valdez A, Portal J, et al. Results of extracorporeal lithotripsy using the MODULITH SLX-MX (STORZ) lithotripter for the treatment of ureteral lithiasis. Rev Cuba Cir, 2014; 49 (3): 24-9.

3. Matlaga BR, Semins MJ. How to improve results with extracorporeal shock wave lithotripsy. Ther Adv Urol. Jun 2009; 1 (2): 99-105.

4. Scales Jr CD, Smith AC, Hanley JM, Saigal CS, Urologic Diseases in America Project. Prevalence of kidney stones in the United States. European urology. 2012 Jul 1;62(1):160-5.

5. Beiko DT, Denstedt JD. Advances in ureterorenoscopy. Urologic Clinics of North America. 2007 Aug 1;34(3):397-408.

6. Monga M, Anderson KJ, Durfee W. Physical properties of flexible ureteroscopes: implications for clinical practice. Journal of endourology. 2004 Jun 1;18(5):462-5.

7. D'Addessi A, Bassi P. Ureterorenoscopy: avoiding and managing the complications. Urologia internationalis. 2011;87(3):251-9.

8. Keeley Francis X, Jr., Dean G. Assimos. Clinical Trials of the Surgical Management of Urolithiasis: Current Status and Future Needs. Adv Chron Kid Dis. 2009; 16: 65-9.

9. Lancina JAM. Urinary lithiasis Present and future. Actas Urol Esp. 2005; 29 (4): 339-44.

10. Sheir KZ. Evaluation of a synchronous twin-pulse technique for shock wave lithotripsy: a prospective randomized study of effectiveness and safety in comparison to standard singlepulse technique. BJU Int. 2008; 101: 1420-1426.

11. Gerber, G. S. (2003). Management of lower-pole caliceal stones. Journal of endourology, 2003; 17(7): 501-503

12. Pearle MS, Lingeman JE, Leveillee $\mathrm{R}$ et al. Prospective, randomized trial comparing shock wave lithotripsy and ureteroscopy for lower pole 
caliceal calculi $1 \mathrm{~cm}$ or less . J Urol $2005 ; 173$ : 2005-9

13. Tiselius HG, Ackermann D, Alken $P$ et al. Guidelines on urolithiasis. Eur Urol 2001; 40 : 362 $-71$

14. Chen RN, Streem SB. Extracorporeal shock wave lithotripsy for lower pole calculi: long-term radiographic and clinical outcome. J Urol 1996; $156: 1572-5$

15. Cass AS. Extra corporeal shock wave lithotripsy or percutaneous nephrolithotomy for lower pole nephrolithiasis? J Endourol 1996; 10: 17 - 20

16. Kumar A, Vasudeva P, Nanda B, Kumar N, Das $\mathrm{M}$, Jha S. K. A prospective randomized comparison between shock wave lithotripsy and flexible ureterorenoscopy for lower caliceal stones $\leq 2 \mathrm{~cm}$ : a single-center experience. Journal of endourology, 2015; 29(5): 575-79.

17. Pearle, M., Clayman, R. V. Outcomes and selection of surgical therapies of stones in the kidney and ureter. Kidney stones: medical and surgical management. Philadelphia: Lippincott-Raven, 1996; 19: 709.

18. Riedler I, Trummer H, Hebel P, Hubmer G. Outcome and safetyof extracorporeal shock wave lithotripsy as first-line therapy of lower pole nephrolithiasis. Urol Int 2003;71:350-4 